\title{
Clinicopathology of Early Gastric Carcinoma: An Update for Pathologists and Gastroenterologists
}

Qin Huang ${ }^{a, c}$ Xiaoping Zou ${ }^{b}$

Departments of a Pathology and ${ }^{\mathrm{b}}$ Gastroenterology, Nanjing Drum Tower Hospital, Nanjing, PR China; ' Department of Pathology and Laboratory Medicine, Veterans Affairs Boston Healthcare System and Harvard Medical School, West Roxbury, MA, USA

\section{Keywords}

Early gastric carcinoma - Stomach · Cancer · Endoscopic submucosal dissection

\begin{abstract}
Background: The WHO defines early gastric carcinoma (EGC) as invasive carcinoma up to the submucosal layer, regardless of nodal metastasis. The recent study results indicate that EGC varies in location, histology, nodal metastasis, and prognosis. Summary: The heterogeneity in EGC may be related to various types of epithelial stem cells. The most important stem cells include $\mathrm{Lgr5}^{+}$cells at the base of a gastric unit in the antrum-pylorus-cardia, Mist $1^{+}$cells at the isthmus $/$ Troy $^{+}$cells at the base in the corpus-fundus, and Sox $2^{+}$cells at the base in almost all regions. Dysregulation of these cells along with environmental factors transform stem cells in different regions into malignancy in genetically susceptible populations. Key Message: The 2 most vulnerable regions for EGC have been found along the lesser curvature: the cardia in elderly patients and antrum-angularis in mid-aged and elderly patients. Most hereditary early-onset gastric carcinomas are concentrated in the corpus-fundus of young women. By histology, the most common EGC type is tubular adenocarcinoma in many growth patterns, starting in the neck of a gastric unit. Worse prognosis has been found in early papillary, compared to tubular, adenocarcinoma, related to deeper penetration, more lymphovascular invasion, and more liver and nodal metastases. Contrary to the common belief, intramucosal signet ring cell carcinoma demonstrates low risk of nodal metastasis, comparable to early intestinal-type EGC. Practical Implications: The overall risk for nodal metastasis in EGC is low but significant. It is urgent to organize multicenter studies on risk of nodal metastasis in EGC in order to establish more reliable clinical practice guidelines to treat EGC patients.
\end{abstract}


Fig. 1. Type and distribution of gastric epithelial stem cells in different regions of the stomach. The gastric diagram was modified from the website of American Cancer Association at http:// w w w . c a n c er . or g / c a n cer / stomachcancer/detailedguide/ stomach-cancer-what-is-stomach-cancer, accessed on July 27, 2016. The information on gastric epithelial stem cell types and locations was from references [27]. +, positive.

Huang and Zou: Clinicopathology of Early Gastric Carcinoma: An Update for Pathologists and Gastroenterologists

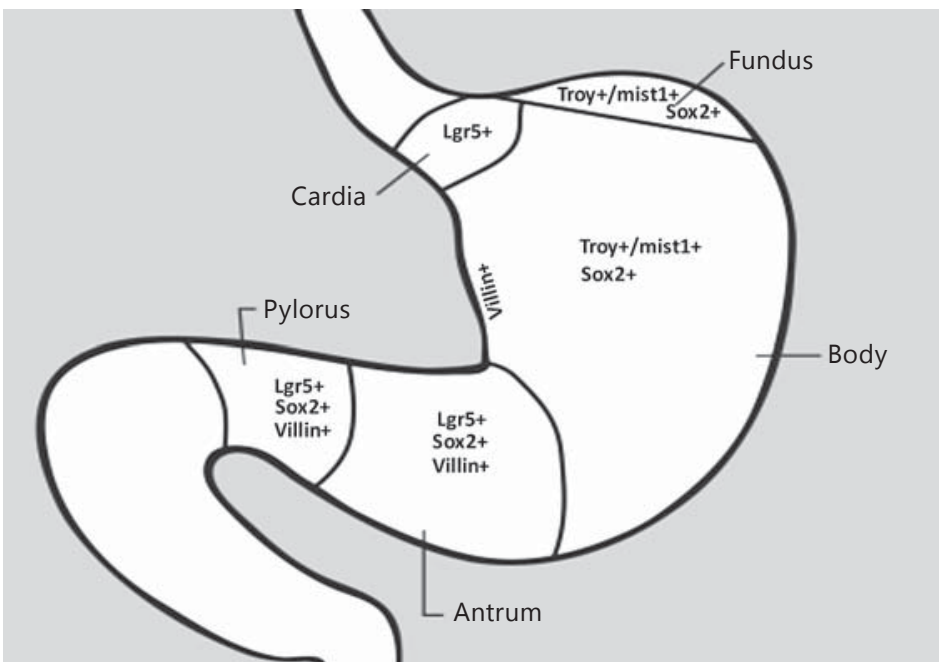

\section{Introduction}

Early gastric carcinoma (EGC) is defined by the World Health Organization as invasive carcinoma of the stomach up to the submucosal layer, regardless of nodal status [1]. Over the past decade, there has been considerable progress in our understanding of the clinicopathology of EGC. In this article, we review the recent advances in histopathology and pathobiology of EGC and discuss the controversial and challenging issues on this cancer.

\section{Heterogeneity of Gastric Epithelial and Stem Cells}

By definition, gastric carcinoma arises in gastric epithelial cells that are heterogeneous and distinguishable histologically in 3 gastric regions: cardia, corpus-fundus, and antrumpylorus (Fig. 1). Embryonically, the gastric self-renewing epithelial cell development is driven by the transcription factor Barx1 through inhibition of Wnt signaling into a mature tubular structure, known as the gastric unit [2]. It has been established that each corpus-fundic gastric unit consists of 5 major terminally differentiated cells: foveolar/pit mucous cells on the surface, mucous cells in the neck, parietal, chief, and endocrine cells in the body and base. All epithelial cells in a gastric unit originate from a single stem cell through clonal expansion, but a single gastric unit may have several stem cells in the human stomach [2,3]. There exist multiple gastric epithelial stem cells that vary in type and distribution among different gastric regions. The most important stem cells include Lgr $5^{+}$cells at the base of a gastric unit in the antrum-pylorus-cardiac regions [2-4], villin ${ }^{+}$cells at the base in the antrum-pylorus, Troy ${ }^{+}$ cells at the base $/$ mist $^{+}$cells at the isthmus in the corpus-fundus, Sox $2^{+}$cells at the base in both the corpus-fundus and the antrum-pylorus [2], and a rare population of villin ${ }^{+}$cells in the lesser curvature of the antrum (Fig. 1) [3, 5, 6]. Apparently, the isthmus of a gastric unit is an important, but no longer the exclusive, stem cell reservoir. Although the downstream targets and molecular biology of those stem cells remain largely elusive, inhibition of Wnt signaling and genetic/epigenetic regulation plays a crucial role in gastric tissue regeneration, plasticity, and carcinogenesis in the antrum-pylorus, probably also in the cardia [2], but not in the corpus [7]. In the corpus, stem cells neither express Lgr5 nor depend upon Wnt signaling for gastric unit development [7]; the expansion of a gastric unit is also much slower in the 
Huang and Zou: Clinicopathology of Early Gastric Carcinoma: An Update for Pathologists and Gastroenterologists

Fig. 2. Distribution of small gastric carcinomas in the size $\leq 2 \mathrm{~cm}$. Reproduced with permission from Huang et al. [13].

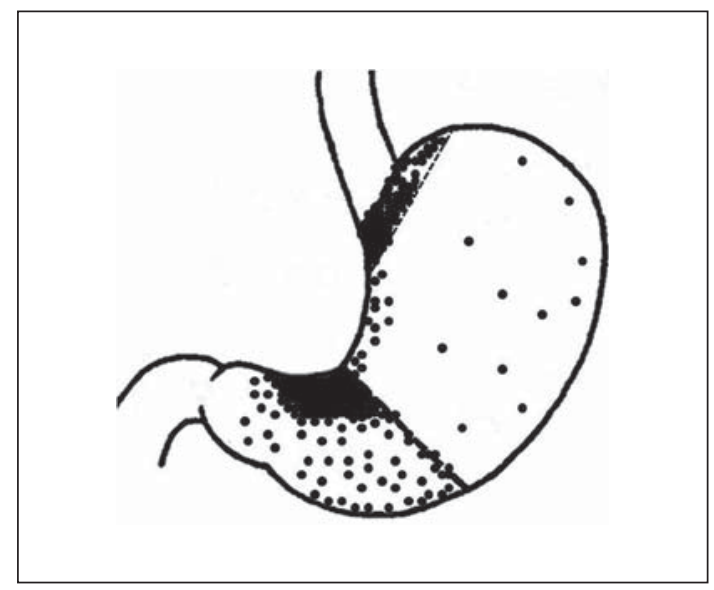

corpus-fundus than in the antrum-pylorus [3,6]. Most recently, Hayakawa et al. [6] discovered the mist $^{+}{ }^{+}$undifferentiated granule-free stem cells in the isthmus of a gastric unit in the mouse corpus, which are capable of: (1) differentiating into all types of epithelial cells; (2) leading to intestinal-like metaplasia and further to intestinal-type intramucosal adenocarcinoma with concomitant induction of the KRAS gene, inactivation of the APC gene, and activation of NOTCH signaling; (3) transforming into signet ring cell-like gastric carcinoma after inactivation of the E-cadherin gene and with Helicobacter felis-induced chronic inflammation. These stem cells constitute the main source of gastric cancer stem cells. Evidently, the existence of various stem cell populations among different gastric regions explains considerable heterogeneity of EGC.

It has been recently established that monoclonal conversion of different gastric stem cells generates 2 groups of gastric glands: (1) the predominant parietal and chief cells in the corpus-fundus, and (2) primarily mucous cells in the antrum-pylorus-cardia [3, 8]. In response to gastric epithelial injury, mainly by environmental factors such as Helicobacter pylori and Epstein-Barr virus-induced chronic inflammation, gastric stem cells in the affected region become dysfunctional, leading to dysregulated differentiation and noncardiac carcinoma [3]. In contrast, neither definitive risk factors nor well-accepted pathogenesis mechanisms have been illustrated for proximal (also known as cardiac) gastric carcinoma [9, 10]. The high diversity and plasticity of gastric epithelial stem cells is responsible for 2 major groups of EGC: proximal cardiac carcinoma and distal noncardiac carcinoma with different epidemiology, pathology, clinical presentation, and prognosis [10]. On the other hand, the hereditary form of early-onset gastric carcinoma is associated with dysregulated gastric stem cells, which occur mainly in the corpus-fundic regions through the CDH-1 gene mutation-related and -unrelated unknown mechanisms $[11,12]$.

\section{Gastric Regions at High Risk for Early Carcinoma}

Once gastric carcinoma is diagnosed at the advanced stage in large size, it is difficult to determine the site of tumor origin. With the widespread use of upper endoscopy, gastric carcinoma has been detected earlier in small size, which makes a systematic investigation of tumor origin possible. In a histopathology study of 313 consecutive small gastric carcinomas in the size of $\leq 2 \mathrm{~cm}$, investigators mapped the location of small gastric carcinoma [13]. As shown in Figure 2, over 68\% (214/313) of small gastric carcinomas grew along the 
Huang and Zou: Clinicopathology of Early Gastric Carcinoma: An Update for Pathologists and Gastroenterologists

lesser curvature in 2 most concentrated areas: cardia $(73.9 \%, 82 / 111)$ and antrum-angularis $(65.3 \%, 132 / 202)$. Very few small gastric carcinomas arose in the corpus [13], which is consistent with the findings of much slower turnover of stem cells in this region $[3,6]$. Further analysis showed considerable differences in clinicopathology between proximal (cardiac) and distal (noncardiac) gastric carcinoma. Compared to distal carcinomas, small proximal gastric carcinomas feature a significantly higher male-to-female ratio (3.1 vs. 1.7, $p<0.05$ ), older mean age (63 years vs. 59, $p<0.05$ ), and the absence of patients younger than 40 years [13]. Similar characteristics have been found in EGCs of the same patient population [14]. The results provide the pathologic evidence on possible Lgr $^{+}{ }^{+}$stem celldriven tumorigenesis mechanism in those 2 areas. The data are also useful for guiding upper endoscopic examination, targeted biopsy, and surveillance, which need to be focused on those 2 high-risk regions for EGC, i.e. the lesser curvature side of the antrum-angularis in patients in 60 years and the cardia for male patients over 40 years. For young women with the family history and clinical suspicion for gastric carcinoma, the corpus and fundus, especially, near the greater curvature, are the most vulnerable regions for early-onset carcinoma [11-13].

\section{Diversity in the Histology of Intramucosal Tubular Adenocarcinoma}

Tubular adenocarcinoma is the most common histologic type of EGC, but controversial for the diagnosis of early tubular adenocarcinoma. The key argument is the definition of invasion that is considered worldwide as the sine qua non diagnostic criterion for carcinoma, except for Japan. In Japan, pathologists diagnose early tubular adenocarcinoma on the basis of primarily nuclear abnormalities with subtle architectural changes, mimicking the letters $\mathrm{W}, \mathrm{H}, \mathrm{Y}$, or $\mathrm{X}$ at low power view $[15,16]$. This practice has been suspected to result in overdiagnosis and overtreatment of EGC in Japan [17]. For a better worldwide communication and research on EGC, several joint consensus conferences have been organized with the participation of both Japanese and Western pathologists. As a result, the Vienna classification of gastrointestinal epithelial neoplasia was published in 2000 [16]. Since then, most Japanese and Western pathologists have reached a certain level of the consensus with regard to the definition of invasion for early tubular adenocarcinoma. In reality, invasion in the gastric lamina propria is difficult to detect on routine histology sections, and there is no reliable/ established pathologic diagnostic criterion for lamina propria invasion. Nevertheless, intramucosal tubular adenocarcinoma has been confirmed to have a low risk of lymph node metastasis $[14,18,19]$ and, therefore, can be safely removed endoscopically. In histopathology, most early tubular adenocarcinomas originate in the isthmus/neck of a gastric unit along the lesser curvature in the distal stomach $[13,20]$. A pathologic diagnosis of early tubular adenocarcinoma requires 2 essential histology features [20-22]:(1) nuclear dysplastic changes with hyperchromasia, nuclear enlargement in the size of 3-4 naïve small lymphocytes, high nuclear-to-cytoplasmic ratio, marked pleomorphism, increased mitotic figures with atypical forms, prominent nucleoli, and cellular immaturity; and (2) architectural abnormalities with a spectrum of growth patterns at low power view, such as anastomosing, fusing, branching, cribriforming, budding, back-to-back crowding, microcysts, disunion, spiky glands with sharp projections, single cell clusters, abortive glands, and necrotic debris in the gland lumens. Recognition of the morphologic characteristics of early tubular adenocarcinoma is crucial in small biopsies to guide patient triage and management, as most patients with early tubular adenocarcinoma are treated by endoscopic, rather than surgical resection in East Asian countries. 
Huang and Zou: Clinicopathology of Early Gastric Carcinoma: An Update for Pathologists and Gastroenterologists

\section{Worse Prognosis for Early Papillary Adenocarcinoma}

Papillary adenocarcinoma is characterized by finger-like projections on the mucosal surface, which is lined with neoplastic columnar cells surrounding a fibrovascular core, and shows micropapillary and tubular components in some tumors. Both papillary and tubular adenocarcinomas in the stomach are grouped as "intestinal" (vs. "diffuse," according to the Lauren classification) [23] or "differentiated" (vs. "undifferentiated," based on the Japanese classification) [24] gastric carcinoma. Recent advances in clinicopathology of early papillary adenocarcinoma have demonstrated the evidence for worse prognosis with deeper penetration, higher frequency of lymphovascular invasion and nodal metastasis, compared to early tubular adenocarcinoma. An early study in 2000 by Yasuda et al. [25] showed a high $(14 \%, 9 / 65)$ rate of liver metastasis in papillary adenocarcinoma with a significantly worse 5 -year survival rate (63 vs. $76 \%$ ) than in nonpapillary carcinomas. More recently, Lee et al. [26] reported a high $(18.3 \%, 9 / 49)$ frequency of lymph node metastasis in early papillary adenocarcinoma of Korean patients. The abovementioned results have been confirmed most recently in Chinese patients $[14,18]$. Compared to early tubular adenocarcinoma, early papillary adenocarcinoma is associated with a significantly worse 5-year survival rate $(80.5 \%$ compared to $96.8 \%$ in early tubular adenocarcinoma, $p<0.05$ ), significantly more submucosal invasion ( $64.4 \mathrm{vs.} 43.6 \%)(p<0.05)$, and the micropapillary growth pattern (6.8 vs. $0 \%)$ $(p<0.003)$ [18]. The cases with a micropapillary growth pattern were all associated with early papillary adenocarcinoma and had a high $(50 \%, 2 / 4)$ nodal metastasis rate, though in a small sample $[14,18]$. Thus, a growing body of the evidence suggests a dismal prognosis in early papillary adenocarcinoma, primarily due to deeper invasion, higher association with the micropapillary growth pattern, more frequent lymphovascular invasion and nodal metastasis. Apparently, early papillary adenocarcinoma should be taken seriously with regard to making the decision for endoscopic resection of this carcinoma.

\section{Low Risk of Nodal Metastasis for Intramucosal Signet Ring Cell Carcinoma}

Signet ring cell carcinoma is well known for dismal prognosis with high risk of nodal and distant metastases, for which radical gastrectomy, rather than endoscopic resection, is preferred. However, recent clinicopathology studies have shown contrasting evidence for intramucosal signet ring cell carcinoma that arises in the isthmus/neck of a gastric unit and is more common in young women, distal stomach with flat and depressed growth patterns [27-31]. A significantly better 5-year overall survival rate has been reported in patients with early signet ring cell carcinoma than in those with non-signet ring cell carcinoma at the same stage [32, 33]. Compared to well-differentiated intestinal-type early adenocarcinoma, intramucosal signet ring cell carcinoma has been found to have a similar incidence of submucosal spread, lymphovascular invasion, and nodal metastasis [30, 31]. Since Hyung et al. [27] reported a very low $(1.6 \%, 3 / 185)$ rate of nodal metastasis for signet ring cell carcinoma at the pT1a stage, a number of studies have confirmed this finding (Table 1) [27-39]. The average frequency of nodal metastasis (based on the data listed in Table 1 ) is only $4.2 \%$ for intramucosal signet ring cell carcinoma, over 5 -fold less for signet ring cell carcinoma with submucosal invasion $(23 \%)$, which has been confirmed by logistic regression analysis of nodal metastasis frequency in early signet ring cell carcinoma between intramucosal and submucosal invasion $[39,40]$. The independent risk factors of nodal metastasis in 1,544 mucosa-confined signet ring cell carcinomas, reported by a Korean multicenter study, include tumor size $>1.7 \mathrm{~cm}$, elevated growth pattern, and lymphovascular invasion [41]. Kim et al. [42] most recently discovered that none of 189 surgical resections of early signet ring cell 


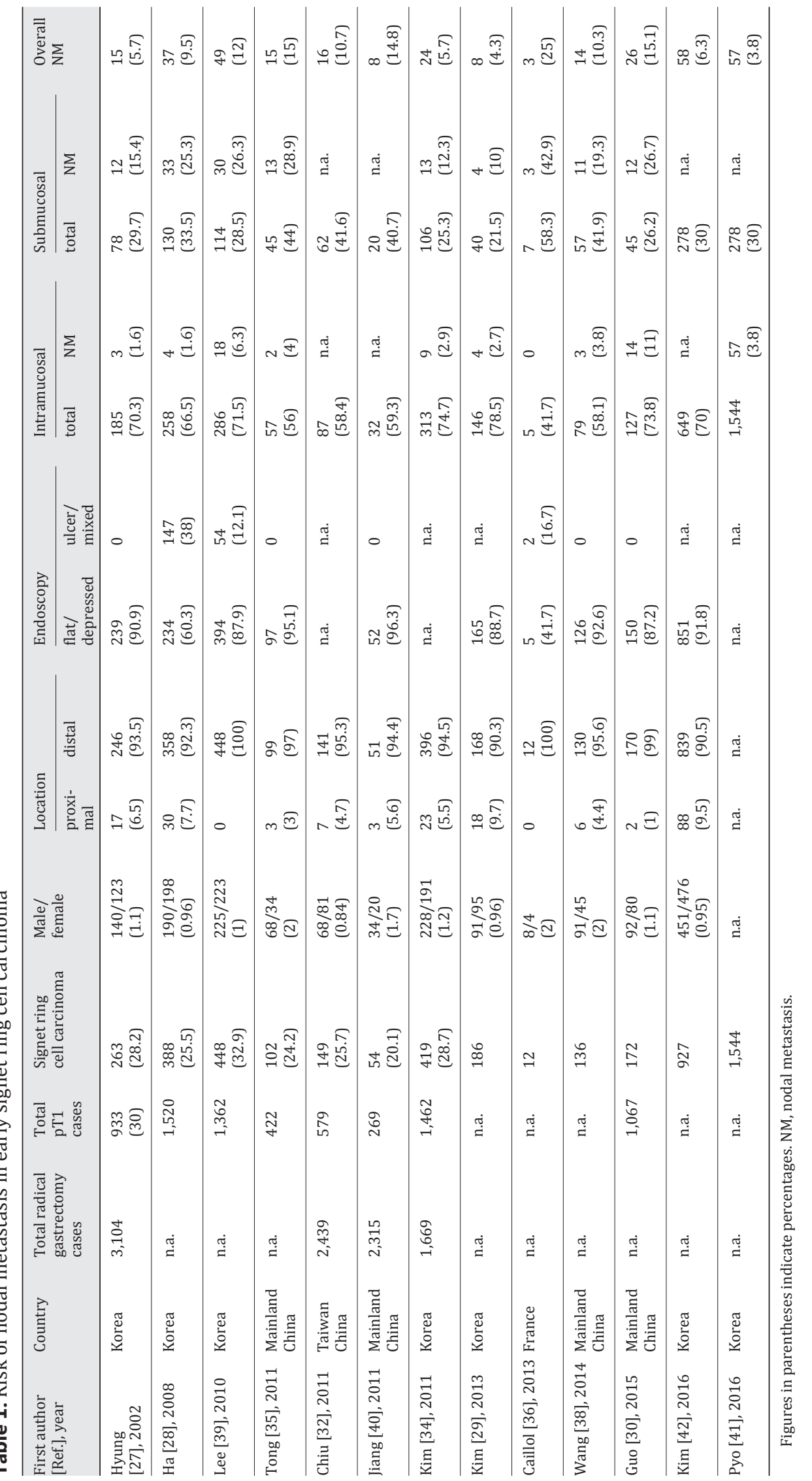


Huang and Zou: Clinicopathology of Early Gastric Carcinoma: An Update for Pathologists and Gastroenterologists

Table 2. Comparison of lymph node metastasis incidence in early gastric carcinoma among Japanese, Korean, and Chinese patients

\begin{tabular}{llll}
\hline Risk factor for nodal metastasis & $\begin{array}{l}\text { Gotoda et al. } \\
{[43], 2000}\end{array}$ & $\begin{array}{l}\text { Kang et al. } \\
{[52], 2010}\end{array}$ & $\begin{array}{l}\text { Huang et al. } \\
{[14], 2015}\end{array}$ \\
\hline $\begin{array}{l}\text { Intramucosal cancer, intestinal type, no LVI, } \\
\leq 3 \mathrm{~cm} \text {, irrespective of ulceration }\end{array}$ & $0 / 1,230(0)$ & $2 / 126(1.6)$ & $1 / 76(1.3)$ \\
\hline $\begin{array}{l}\text { Intramucosal cancer, intestinal type, no LVI, } \\
\text { any size, without ulceration }\end{array}$ & $0 / 929(0)$ & $2 / 146(1.4)$ & $0 / 64(0)$ \\
$\begin{array}{l}\text { Intramucosal cancer, diffuse type, no LVI, } \\
\leq 3 \mathrm{~cm}, \text { without ulceration }\end{array}$ & $0 / 141(0)$ & 0 & $3 / 30(10)$ \\
$\begin{array}{l}\text { Submucosal cancer, sm1 }(\leq 500 \mu \mathrm{m}), \text { intestinal } \\
\text { type, no LVI, } \leq 3 \mathrm{~cm}\end{array}$ & $0 / 145(0)$ & $3 / 20(15.0)$ & $3 / 27(11.1)$ \\
\hline
\end{tabular}

Figures in parentheses indicate percentages. LVI, lymphovascular invasion.

carcinoma in the size smaller than $2 \mathrm{~cm}$ without ulceration demonstrated nodal metastasis, suggesting that endoscopic resection may be an effective and safe alternative to surgical gastrectomy for intramucosal signet ring cell carcinoma under certain circumstances. Indeed, not all patients with early signet ring cell carcinoma should be resected endoscopically, especially for hereditary CDH1-gene mutation-associated signet ring cell carcinoma, for which total gastrectomy may be a better and safer option because of the multifocal tumor growth pattern [11]. Therefore, an individualized approach may maximize the benefits of modern endoscopic resection technology and minimize the risk of tumor metastasis.

\section{Unsettled Risk Factors of Lymph Node Metastasis}

Once EGC is diagnosed, endoscopic resection, such as endoscopic mucosal resection or endoscopic submucosal dissection (ESD), is the treatment of choice in East Asian countries and also serves as an excellent staging modality. This practice is not commonly carried out in the West, probably because of the rarity of gastric carcinoma. The rationale behind this endoscopic resection strategy is the extremely low risk for nodal metastasis in EGC, according to the study results of 5,265 EGC radical gastrectomy cases accumulated before year 2000 at the Japanese National Cancer Center Hospital [43]. In that study, Gotoda et al. [43] reported the absence of nodal metastasis in 4 groups of EGC patients (Table 2). As a result, the current ESD practice guidelines in Japan and China require 3 extended indications: (1) intestinal-type intramu cosal carcinoma of any size without ulcer; (2) intestinal-type intramucosal carcinoma with ulcer but in the size smaller than $3 \mathrm{~cm}$; and (3) diffuse-type EGC in the size smaller than $3 \mathrm{~cm}$ with superficial $(<0.5 \mathrm{~mm}$ in depth) submucosal invasion, but without lymphovascular invasion $[44,45]$. While lymphovascular invasion has been confirmed worldwide as the most important risk factor for nodal metastasis in EGC [19, 46, 47], an extremely low frequency of nodal metastasis in EGC for intramucosal carcinoma, tumor size smaller than $2 \mathrm{~cm}$, and superficial submucosal invasion without lymphovascular invasion, reported previously [43], has not been universally confirmed (Table 2). Several recent Chinese and Korean studies on nodal metastasis in EGC also demonstrate different risk factors such as female gender $[18,19,48]$, intestinal type [47], and distal gastric location [18, 49, 50], but not ulceration [18, 49, 51]. A 
Huang and Zou: Clinicopathology of Early Gastric Carcinoma: An Update for Pathologists and Gastroenterologists

most recent systematic review of the world literature in 42 qualified studies shows low, but substantial, nodal metastasis rates of $6 \%$ for intramucosal carcinoma, $9 \%$ for EGC without lymphovascular invasion, 13\% for the intestinal-type EGC, 13\% for EGC with an elevated growth pattern, and 8\% for EGC in the size smaller than $2 \mathrm{~cm}$ [47]. In Korea, Kang et al. [52] reported an overall $12.6 \%$ nodal metastasis rate in 478 EGC radical resection cases, and no relationship was found between clinicopathologic features and nodal metastasis in 270 pT1a tumors (Table 2), parallel to the findings in Chinese patients $[14,18]$. Importantly, the current criteria for extended indications for ESD were found to be problematic for prediction of risk of nodal metastasis in intramucosal signet ring cell carcinoma (Tables 1,2). Thus, a growing body of evidence acquired in the most recent years worldwide highlights a serious legitimate concern about a low, but considerable, risk of nodal metastasis in EGC for the presumed risk factors that were considered minimal or none in the earlier study [43].

\section{Conclusions}

EGC is heterogeneous in location, growth pattern, histology, and pathogenesis, which may be related to malignant transformation of various types of gastric epithelial stem cells. As such, each EGC patient should be treated individually and precisely with the consideration of unique hereditary, genetic/epigenetic, clinicopathologic, and environmental factors. A brief review of the most recent literature suggests a low but significant level of risk for nodal metastasis in EGC patients. This risk cannot be ignored since the presence of nodal metastasis is a contraindication for endoscopic resection. We may have to face the challenges in quantifying the risk of nodal metastasis in EGC of individual patients for an optimal management strategy. It is urgent to organize multicenter studies with large samples in different ethnic patient populations to better delineate the risk of nodal metastasis in EGC patients for establishment of more accurate and reliable clinical practice guidelines on EGC.

\section{Acknowledgements}

We are grateful to Cheng Fang, MD, PhD, of Department of Gastroenterology of the Zhejiang University Affiliated Second Hospital in Hangzhou for critical review and technical assistance.

\section{Disclosure Statement}

The authors declare no conflict of interest.

\section{References}

1 Lauwers GY, Carneiro F, Graham DY, et al: Gastric carcinoma; in Bosman FT, Carneiro F, Hruban RH, Theise ND (eds): WHO Classification of Tumours of the Digestive System. Lyon, IARC Press, 2010, pp 48-58.

2 Aloia L, Mckie MA, Huch M: Cellular plasticity in the adult liver and stomach. J Physiol 2016;594:4815-4825.

3 Hoffmann W: Current status on stem cells and cancers of the gastric epithelium. Int J Mol Sci 2015;16:1915319169.

4 Quante M, Bhagat G, Abrams JA, et al: Bile acid and inflammation activate gastric cardia stem cells in a mouse model of Barrett-like metaplasia. Cancer Cell 2012;21:36-51.

5 Brungs D, Aghmesheh M, Vine KL, et al: Gastric cancer stem cells: evidence, potential markers, and clinical implications. J Gastroenterol 2016;51:313-326.

6 Hayakawa Y, Ariyama H, Stancikova J, et al: Mist1 expressing gastric stem cells maintain the normal and neoplastic gastric epithelium and are supported by a perivascular stem cell niche. Cancer Cell 2015;28:800814. 
7 Mills JC, Shivdasani RA: Gastric epithelial stem cells. Gastroenterology 2011;140:412-424.

8 McDonald SA, Greaves LC, Gutierrez-Gonzalez L, et al: Mechanisms of field cancerization in the human stomach: the expansion and spread of mutated gastric stem cells. Gastroenterology 2008;134:500-510.

9 Fang C, Lu L, Shi J, et al: Risk factors of early proximal gastric carcinoma in Chinese diagnosed with the WHO criteria. J Dig Dis 2015;16:327-336.

10 Huang Q, Sun Q, Fan XS, Zhou D, Zou XP: Recent advances in proximal gastric carcinoma. J Dig Dis, Epub ahead of print.

11 Fujita H, Lennerz JK, Chung DC, et al: Endoscopic surveillance of patients with hereditary diffuse gastric cancer: biopsy recommendations after topographic distribution of cancer foci in a series of 10 CDH1-mutated gastrectomies. Am J Surg Pathol 2012;36:1709-1717.

12 Zhou F, Shi J, Fang C, Zou XP, Huang Q: Gastric carcinomas in young (younger than 40 years) Chinese patients: clinicopathology, family history, and post-resection survival. Medicine (Baltimore) 2016;95:e2873.

13 Huang Q, Shi J, Sun Q, et al: Clinicopathologic characterization of small $(\leq 2 \mathrm{~cm})$ proximal and distal gastric carcinomas in a Chinese population. Pathology 2015;47:526-532.

14 Huang Q, Fang C, Shi J, et al: Differences in clinicopathology of early gastric carcinoma between proximal and distal location in 438 Chinese patients. Sci Rep 2015;5:13439.

15 Kato Y, Yanagisawa A, Sugano H: Biopsy interpretation in diagnosis of gastric carcinoma; in Nishi M, Ichikawa H, Nakajima T, et al (eds): Gastric Cancer. Tokyo, Springer, 1993, pp 133-150.

16 Schlemper RJ, et al: The Vienna classification of gastrointestinal epithelial neoplasia. Gut 2000;47:251-255.

17 Everett SM, Axon AT: Early gastric cancer: disease or pseudo-disease? Lancet 1998;351:1350-1352.

18 Fang C, Shi J, Sun Q, et al: Risk factors of lymph node metastasis in early gastric carcinomas diagnosed with WHO criteria in 379 Chinese patients. J Dig Dis, Epub ahead of print.

19 Jin EH, Lee DH, Jung SA, et al: Clinicopathologic factors and molecular markers related to lymph node metastasis in early gastric cancer. World J Gastroenterol 2015;21:571-577.

20 Okamoto N, Kawachi H, Yoshida T, et al: "Crawling-type" adenocarcinoma of the stomach: a distinct entity preceding poorly differentiated adenocarcinoma. Gastric Cancer 2013;16:220-232.

21 Kang KJ, Kim KM, Kim JJ, et al: Gastric extremely well-differentiated intestinal-type adenocarcinoma: a challenging lesion to achieve complete endoscopic resection. Endoscopy 2012;44:949-952.

22 Ushiku T, Arnason T, Ban S, et al: Very well-differentiated gastric carcinoma of intestinal type: analysis of diagnostic criteria. Mod Pathol 2013;26:620-1631.

23 Lauren P: The two histological main types of gastric carcinoma: diffuse and so-called intestinal-type carcinoma. An attempt at a histo-clinical classification. Acta Pathol Microbiol Scand 1965;64:31-49.

24 Japanese Gastric Cancer Association: Japanese classification of gastric carcinoma: 3rd English edition. Gastric Cancer 2011;14:101-112.

25 Yasuda K, Adachi Y, Shiraishi N, Maeo S, Kitano S: Papillary adenocarcinoma of the stomach. Gastric Cancer 2000;3:33-38.

26 Lee HJ, Kim GH, Park DY, et al: Is endoscopic submucosal dissection safe for papillary adenocarcinoma of the stomach? World J Gastroenterol 2015;21:3944-3952.

27 Hyung WJ, Noh SH, Lee JH, et al: Early gastric carcinoma with signet ring cell histology. Cancer 2002;94:78-83.

28 Ha TK, An JY, Youn HK, Noh JH, Sohn TS, Kim S: Indication for endoscopic mucosal resection in early signet ring cell gastric cancer. Ann Surg Oncol 2008;15:508-513.

29 Kim JY, Kim YY, Kim SJ, et al: Predictive factors for lymph node metastasis in signet ring cell gastric cancer and the feasibility of endoscopic submucosal dissection. J Gastric Cancer 2013;13:93-97.

30 Guo CG, Zhao DB, Liu Q, et al: Risk factors for lymph node metastasis in early gastric cancer with signet ring cell carcinoma. J Gastrointest Surg 2015;19:1958-1965.

31 Lee SH, Jee SR, Kim JH, Seol SY: Intramucosal gastric cancer: the rate of lymph node metastasis in signet ring cell carcinoma is as low as that in well-differentiated adenocarcinoma. Eur J Gastroenterol Hepatol 2015;27: 170-174.

32 Chiu CT, Kuo CJ, Yeh TS, et al: Early signet ring cell gastric cancer. Dig Dis Sci 2011;56:1749-1756.

33 Gronnier C, Messager M, Robb WB, et al: Is the negative prognostic impact of signet ring cell histology maintained in early gastric adenocarcinoma? Surgery 2013;154:1093-1099.

34 Kim HM, Pak KH, Chung MJ, et al: Early gastric cancer of signet ring cell carcinoma is more amenable to endoscopic treatment than is early gastric cancer of poorly differentiated tubular adenocarcinoma in select tumor conditions. Surg Endosc 2011;25:3087-3093.

35 Tong JH, Sun Z, Wang ZN, et al: Early gastric cancer with signet-ring cell histologic type: risk factors of lymph node metastasis and indications of endoscopic surgery. Surgery 2011;149:356-363.

36 Caillol F, Bories E, Guiramand J, et al: Can we resect EGC with Signet ring cells in Europe? J Gastrointest Cancer 2013;44:422-427.

37 Park JM, Kim SW, Nam KW, et al: Is it reasonable to treat early gastric cancer with signet ring cell histology by endoscopic resection? Analysis of factors related to lymph-node metastasis. Eur J Gastroenterol Hepatol 2009; 21:1132-1135.

38 Wang Z, Zhang X, Hu J, et al: Predictive factors for lymph node metastasis in early gastric cancer with signet ring cell histology and their impact on the surgical strategy: analysis of single institutional experience. J Surg Res 2014;191:130-133. 
39 Lee JH, Choi IJ, Kook MC, Nam BH, Kim YW, Ryu KW: Risk factors for lymph node metastasis in patients with early gastric cancer and signet ring cell histology. Br J Surg 2010;97:732-736.

40 Jiang CG, Wang ZN, Sun Z, Liu FN, Yu M, Xu HM: Clinicopathologic characteristics and prognosis of signet ring cell carcinoma of the stomach: results from a Chinese mono-institutional study. J Surg Oncol 2011;103:700703.

41 Pyo JH, Shin CM, Lee H, et al: A risk-prediction model based on lymph-node metastasis for incorporation into a treatment algorithm for signet ring cell-type intramucosal gastric cancer. Ann Surg 2016;264:1038-1043.

$42 \mathrm{Kim} \mathrm{YH,} \mathrm{Kim} \mathrm{JH,} \mathrm{Kim} \mathrm{H,} \mathrm{et} \mathrm{al:} \mathrm{Is} \mathrm{the} \mathrm{recent} \mathrm{WHO} \mathrm{histological} \mathrm{classification} \mathrm{for} \mathrm{gastric} \mathrm{cancer} \mathrm{helpful} \mathrm{for} \mathrm{appli-}$ cation to endoscopic resection? Gastric Cancer 2016;19:869-875.

43 Gotoda T, Yanagisawa A, Sasako M, et al: Incidence of lymph node metastasis from early gastric cancer: estimation with a large number of cases at two large centers. Gastric Cancer 2000;3:219-225.

44 Japanese Gastric Cancer Association: Japanese gastric cancer treatment guidelines 2010 (ver. 3). Gastric Cancer 2011;14:113-123.

45 Chinese Society of Digestive Endoscopy: Consensus for early gastric carcinoma diagnosis and treatment in China. Chin J Dig Endosc 2014;31:361-377.

46 Ahmad R, Setia N, Schmidt BH, et al: Predictors of lymph node metastasis in Western early gastric cancer. J Gastrointest Surg 2016;20:531-538.

47 Barreto SG, Windsor JA: Redefining early gastric cancer. Surg Endosc 2016;30:24-37.

48 Guo TJ, Qin JY, Zhu LL, et al: Feasible endoscopic therapy for early gastric cancer. World J Gastroenterol 2015; 21:13325-13331.

49 Yang HJ, Kim SG, Lim JH, et al: Predictors of lymph node metastasis in patients with non-curative endoscopic resection of early gastric cancer. Surg Endosc DOI: 10.1007/s00464-014-3780-7.

50 Zhao BW, Chen YM, Jiang SS, et al: Lymph node metastasis, a unique independent prognostic factor in early gastric cancer. PLoS One 2015;10:e0129531.

51 Park JH, Lee SH, Park JM, et al: Prediction of the indication criteria for endoscopic resection of early gastric cancer. World J Gastroenterol 2015;21:11160-11167.

52 Kang HJ, Kim DH, Jeon TY, et al: Lymph node metastasis from intestinal-type early gastric cancer: experience in a single institution and reassessment of the extended criteria for endoscopic submucosal dissection. Gastrointest Endosc 2010;72:508-555. 